\title{
LOS SALARIOS REALES Y EL NIVEL DE VIDA EN UNA ECONOMÍA LATINOAMERICANA COLONIAL: MONTEVIDEO ENTRE 1760-1810*
}

\author{
MARÍA INÉS MORAES \\ Universidad de la República ${ }^{\mathrm{a}}$ \\ FLORENCIA THUL \\ Universidad de la República ${ }^{\mathrm{a}}$
}

Real wages and living standards in a Latin American colonial economy: Montevideo, 1760-1810

\begin{abstract}
This article makes a contribution to the empirical and methodological discussion on the standard of living in Latin America during the colonial period. It presents evidence obtained from primary sources on the evolution of nominal wages, cost of living and real wages for 10 occupational categories in the region of Montevideo between 1760 and 1810. The results place rural laborers and masons in Montevideo below subsistence levels until at least the first decade of the $19^{\text {th }}$ century, a finding that is difficult to reconcile with the demographic and productive growth of the region at the same time. Wages may not be the main component in the structure of family income among the subordinate sectors of the colonial Río de la Plata.
\end{abstract}

Keywords: living standards, real wages, Latin America, Río de la Plata.

JEL codes: N16, N36

* Received 29 December 2016. Accepted 4 August 2017. La investigación en la que se basa este texto fue financiada por la Agencia Nacional de Investigación e Innovación (Uruguay) y la Comisión Sectorial de Investigación Científica de la Universidad de la República (Uruguay) durante los años 2014-2017. Resultados preliminares de investigación fueron presentados en XIV Jornadas de Historia de la Universidad Torcuato Di Tella realizadas en Buenos Aires el 6 y 7 de noviembre de 2014 y en el simposio "Welfare, inequality and standards of living compared: America, Europe and Asia, ca. 1500-2000" en el XVII th Economic History Congress (WEHC), realizado en Kyoto el 3-7 de Agosto de 2015. Las autoras agradecen los valiosos aportes recibidos de los colegas que participaron en esas actividades, así como de los evaluadores de la revista.

a Instituto de Economía de la Facultad de Ciencias Económicas y Administración, Joaquín Requena 1375 CP 11200 (Montevideo - Uruguay). Email: imoraes@ccee.edu.uy, florenciathul@ gmail.com 


\section{RESUMEN}

Este artículo hace una contribución a la discusión empírica y metodológica sobre el nivel de vida en América Latina durante el período colonial. Presenta evidencia obtenida de fuentes primarias sobre la evolución de los salarios nominales, el costo de vida y los salarios reales para diez categorías ocupacionales en la región de Montevideo entre 1760-1810. Los resultados colocan a los peones rurales y albañiles montevideanos por debajo de niveles de subsistencia hasta por lo menos la primera década del siglo XIX, una constatación que resulta difícil de compatibilizar con el crecimiento demográfico y productivo de la región en la misma época. Los salarios posiblemente no fueran el ingreso principal de amplios sectores subalternos.

Palabras clave: nivel de vida, salarios reales, América Latina, Río de la Plata

\section{INTRODUCCIÓN}

Este artículo hace una contribución a la discusión sobre el nivel de vida en América Latina durante el período colonial. Presenta evidencia obtenida de fuentes primarias sobre la evolución de los salarios nominales, el costo de vida y los salarios reales en la ciudad de Montevideo entre 1760-1810. Estos resultados son empleados para comparar la evolución del salario real de los trabajadores libres de Montevideo con la de similares de otras regiones de América hispana y Europa en el mismo período.

La cuestión del nivel de vida de los habitantes de América Latina en los períodos pre-industriales ha cobrado renovado interés en la literatura reciente sobre el atraso relativo de la región (North, Summerhill, y Weingast 1999) (Acemoglu, Johnson, y Robinson 2001) (Acemoglu, Johnson, y Robinson 2002) (Acemoglu y Robinson 2012) (Bruhn y Gallego 2012). La hipótesis que encuentra las razones del atraso latinoamericano en las instituciones coloniales avivó el interés por disponer de indicadores sobre el nivel de vida de los habitantes de América Latina en diferentes períodos históricos.

Entre los indicadores analizados por los especialistas ha concitado especial interés el salario real. Comparar el poder de compra del salario de los trabajadores en diversas partes del mundo y períodos de la historia se presenta como una estrategia ventajosa, con respecto a estrategias comparativas clásicas como las estimaciones del PIB por habitante (Allen 2001) (Broadberry y Gupta 2006) (Allen et al. 2011) (Arroyo-Abad, Davies, y van Zanden 2012). 
En este marco se ha entablado un debate sobre la evolución de los salarios reales en América Latina desde el 1600 hasta el siglo XIX. Algunos autores sostienen que los salarios reales eran de modo general más bajos en la América Hispana que en la América anglosajona ya desde el siglo XVI, y que esta temprana brecha salarial constituye la principal explicación de la divergencia en niveles de vida que caracteriza el presente de ambas regiones (Allen, Murphy, y Schneider 2012). Si bien los defensores de esta hipótesis reconocen que este panorama general admite excepciones (como el caso de los salarios reales de la región del Río de la Plata, donde el precio de algunos alimentos era muy bajo) han afirmado también que estas situaciones excepcionales no modifican un panorama general de temprano atraso relativo de la América española con respecto a la América anglosajona, así como con las áreas más dinámicas de Europa (Allen, Murphy, y Schneider 2012).

Esta afirmación ha sido confrontada por trabajos que han ofrecido evidencias donde el nivel de los salarios reales de los trabajadores de algunas ciudades latinoamericanas durante el siglo XVIII se muestra superior (Dobado y García Montero 2010) o similar (Challú y Gómez-Galvarriato 2015) al de sus pares de las zonas más desarrolladas de Europa.

Esta confrontación entre lo que ha dado en llamarse la posición "optimista" y la "pesimista" sobre los salarios reales en América Latina en el período colonial (Dobado-González 2015) dio lugar a una controversia en torno a la estrategia de comparación entre salarios reales de diversas regiones, que ha sido empleada en diversos trabajos a partir de una propuesta originalmente formulada por Robert Allen (Allen 2001). En su versión más simple la estrategia en cuestión tiene tres pasos: el primer paso consiste en definir el contenido y el precio de una cesta mínima de supervivencia para una familia asalariada en una economía pre-industrial; el segundo consiste en medir cuántas cestas de supervivencia puede comprar con su salario un albañil de la/s región/es de interés (este indicador recibe el nombre de "ratio de bienestar"), el tercero consiste en comparar las "ratios de bienestar" de albañiles de diferentes regiones (Allen et al. 2011; Allen, Murphy, y Schneider 2012; Arroyo-Abad, Davies, y van Zanden 2012; Arroyo Abad 2013; Allen, Murphy, y Schneider 2015). En algunos trabajos el esquema básico tuvo modificaciones, con la introducción de una cesta de consumo familiar menos austera ("respetable") y la incorporación de categorías ocupacionales adicionales a la del albañil (Challú y Gómez-Galvarriato 2015).

El debate metodológico en torno a esta estrategia ha cuestionado el significado de los albañiles como categoría representativa del trabajo asalariado en las economías pre-industriales (González Mariscal 2014), la simplicidad de la cesta de consumo, así como su universalidad (González Mariscal 2014; Dobado-González 2015) y finalmente la significación del salario real como indicador de niveles de bienestar (Djenderedjan y Martirén 2015). En respuesta, los defensores del método han defendido el potencial comparativo de la estrategia metodológica y su adecuada replicabilidad en 
diversos contextos temporales y espaciales (Allen, Murphy, y Schneider 2015; Arroyo-Abad y Van Zanden 2015).

Este trabajo busca contribuir a esta discusión, tanto en su dimensión empírica como metodológica, con evidencia sobre los asalariados de la región de Montevideo entre 1760 y 1810. Presenta por primera vez salarios nominales para diversas categorías ocupacionales rurales y urbanas, cualificadas y no cualificadas, recogidos de fuentes primarias. Propone una adaptación de la cesta europea de supervivencia y replica el ejercicio metodológico ya aplicado a otras ciudades del mundo y la región, que consiste en estimar la ratio de bienestar de albañiles, así como de otras ocupaciones representativas del trabajo local. Finalmente compara los resultados obtenidos con los de otras ciudades de América Hispana colonial y reflexiona sobre los límites y posibilidades del ejercicio. El apartado 2 presenta las fuentes y la metodología. En los apartados 3 a 6 se presentan los resultados obtenidos. El apartado 7 resume las principales conclusiones.

\section{FUENTES Y METODOLOGÍA}

Este trabajo presenta, en primer lugar, evidencia sobre algunas características de la oferta y la demanda de trabajo asalariado en Montevideo colonial, así como sobre el nivel del salario nominal de tres grandes grupos de asalariados y su evolución en el período 1760-1810. Las categorías ocupacionales seleccionadas son: el grupo de los albañiles y ocupaciones afines, el grupo de trabajadores portuarios de la guardia costera, y el grupo de los trabajadores rurales.

En segundo lugar se propone una cesta de consumo de supervivencia elaborada con los mismos criterios que Allen (2001), donde son tomadas en cuenta las pautas alimentarias locales y los precios locales de los bienes consumidos.

En tercer lugar, se da a conocer una estimación de la ratio de bienestar para 10 categorías ocupacionales entre 1760-1810, que surge de calcular la cantidad de cestas de supervivencia que pueden comprar los trabajadores libres con sus ingresos salariales.

La evidencia empleada proviene de tres conjuntos documentales. El primero de ellos son los registros contables de las remuneraciones pagadas al personal empleado en la reconstrucción de la Iglesia Matriz de Montevideo, generados desde 1788 hasta $1808^{1}$. Los datos que la fuente aporta son: nombre del trabajador, categoría ocupacional, período de trabajo por el que se paga, remuneración expresada como salario mensual o jornal expresado

\footnotetext{
1 Archivo General de la Nación (Argentina), Sala IX, 03-02-05, División Colonia, Sección Gobierno Montevideo, Iglesia Matriz, Cuentas, 1781-1808. La única iglesia de la ciudad de Montevideo se derrumbó en el año 1787. La construcción de un nuevo templo comenzó en noviembre de 1790 y se prolongó hasta 1808 (Capillas de Castellanos 1968).
} 
en pesos y/o reales, paga total efectuada a cada trabajador. El registro era llevado por el capataz de la obra, quien rendía cuentas ante las autoridades eclesiásticas.

El segundo conjunto son los registros contables de las remuneraciones pagadas al personal empleado en la construcción de las fortificaciones construidas para la defensa de Montevideo (muralla y baterías de la ciudad) entre 1760 y $1800^{2}$. La documentación registra el nombre de los trabajadores, su categoría ocupacional, los días trabajados y la paga percibida, mensual o diaria según el caso.

El tercer cuerpo documental empleado son las cartas-cuenta que presentaba ante la Junta de Hacienda el funcionario a cargo de la Caja Real de Montevideo durante el período $1775-1799^{3}$. De aquí se obtuvieron las remuneraciones pagadas al personal empleado en el servicio de vigilancia costera y en las "estancias del rey". El servicio de vigilancia costera cumplía funciones regulares de control de las costas de Montevideo para evitar arribadas ilegales, y de los barcos llegados al puerto de forma legal, para evitar la entrada de mercaderías de forma ilegal. El personal de vigilancia estaba conformado por patrones de botes y marineros, respondía a las autoridades de la Aduana y por lo tanto, a la Real Hacienda. La información sobre la paga de estos trabajadores entre 1760-1775, cuando todavía no existía una Caja Real en Montevideo, se obtuvo de los libros manuales generados en la Aduana de Montevideo ${ }^{4}$.

Las "estancias del rey", por su parte, eran dos establecimientos ganaderos de propiedad de la Corona (estancia de Tala y estancia del Cerro) administrados por los gobernadores militares de la ciudad. Tenían como cometido principal proporcionar y cuidar la caballada requerida para maniobras militares. Según el grado de organización que alcanzara, una estancia real podía también producir carne, cueros e incluso otros abastos para el alimento de guarniciones militares. Por su dependencia con la figura del gobernador, quien también era la mayor autoridad militar dentro de la jurisdicción de Montevideo, los capataces ocupados en este tipo de establecimientos en muchos casos eran soldados. Las estancias del rey cumplían una importante función de apoyo logístico durante las misiones militares, razón por la que en ocasiones incorporaban durante prolongados períodos, personal civil versado en el transporte y la caminería, como "baquianos", carpinteros y carreteros. La información sobre la paga del personal de las estancias del rey entre 1760-1775, cuando todavía no existía una Caja Real en Montevideo, se obtuvo de los libros manuales generados por el Oficial Real que llevaba las cuentas de la Real Hacienda ${ }^{6}$.

\footnotetext{
2 Archivo General de la Nación, (Uruguay), Archivo General Administrativo, Cajas cronológicas, 1758-1800 (más detalles al final del texto).

3 Archivo General de Indias (España), Buenos Aires, 445-446 y 448.

4 Archivo General de la Nación (Uruguay), AGA, Libro 161.

5 Conocedores de caminos.

6 Archivo General de la Nación (Uruguay), AGA, Libro 161.
} 


\section{SINGULARIDADES DEL TRABAJO ASALARIADO EN MONTEVIDEO COLONIAL}

La región de Montevideo corresponde a la ciudad sudamericana del mismo nombre, fundada por la Corona española en 1726 en la orilla norte del Río de la Plata, y los territorios comprendidos dentro de su jurisdicción administrativa. Durante el siglo XVIII Montevideo y Buenos Aires formaban parte de un mismo espacio económico en torno al Río de la Plata, caracterizado por ser un espacio de frontera con el vecino Brasil portugués y de conexión con el Atlántico. La primera de las características mencionadas dio un marcado papel de bastión militar defensivo a ambas ciudades, y la segunda hizo del comercio legal e ilegal un factor crucial de su vida económica.

Durante el período analizado en este artículo el espacio económico del Río de la Plata experimentó un proceso de crecimiento económico y demográfico (Gelman y Moraes 2014). La región de Montevideo -la más recientemente incorporada al mundo colonial y también la más pequeña en población- vivió el proceso de manera intensa. De acuerdo a estimaciones recientes, en el período colonial la población de la jurisdicción de Montevideo habría pasado de menos de 3000 habitantes en 1760 a poco más de 30.000 en 1810 (Pollero y Sagaseta 2015), mientras que su producción agraria se multiplicó por un coeficiente de 5.3 (Moraes 2014). No se conocen estimaciones globales de la evolución de la actividad portuaria de Montevideo para todo el período, pero en el marco de la ampliación del comercio promovida en 1778, las exportaciones legales del producto local más importante -los cueros bovinos- pasaron de un volumen del orden de las 20 mil unidades en la década de 1760 a cerca de 300 mil en la de 1790 (Moraes y Stalla 2011). Así, la región de Montevideo ejemplifica muy bien el caso de unas regiones periféricas del mundo hispanoamericano que experimentaron, en el marco de las reformas borbónicas, un proceso acelerado de intensificación del comercio, expansión de la frontera agrícola, crecimiento demográfico y expansión económica.

La característica más importante del mercado de trabajo en el Montevideo colonial fue la escasez de mano de obra. El reducido tamaño de la población de la ciudad y su jurisdicción fue uno de los factores determinantes de esa escasez. Si se asume que el territorio legal de la jurisdicción de Montevideo totalizaba aproximadamente unos $15.000 \mathrm{~km}^{2}$ se obtienen -sin contar las poblaciones indígenas errantes- densidades de población muy bajas, del orden de 0.2 habitantes por $\mathrm{km}^{2}$ en 1760 y de 2 habitantes por $\mathrm{km}^{2}$ en 1810. En 1778 el 77\% de la población europea, africana y criolla que formaba parte del mundo colonial vivía en la ciudad intramuros, y el 23\% en la campaña próxima a la ciudad. Pero hacia 1803 el porcentaje de la población que vivía intramuros había caído a 66\%, fenómeno que se relaciona con la consolidación y ampliación de la 
ocupación de áreas rurales contiguas al casco urbano. En 1778 la población afincada en la ciudad de Montevideo y su hinterland agrario más cercano estaba compuesta por un $71,7 \%$ de blancos, 1,3\% de indios, $20,8 \%$ de negros y $6,3 \%$ de pardos. En ese territorio que apenas empezaba a poblarse los hombres eran mayoría y el índice de masculinidad era, por lo tanto, muy elevado (140) (Pollero 2016). Este dato se asocia con el flujo continuo de migrantes de otras zonas americanas, que arribaron a la jurisdicción montevideana -al igual que a todo el Litoral rioplatense- atraídos por las oportunidades de establecerse en un espacio dinámico y de frontera abierta. La naturaleza defensiva de la ciudad, por su parte, radicaba por períodos prolongados a personal militar y naval en la plaza.

Fue después de 1760, cuando se estabilizó la frontera con las poblaciones nativas no sometidas a control colonial, que empezó a ocuparse con cierta estabilidad el área rural del espacio montevideano Los recursos naturales de la jurisdicción de Montevideo la hacían sumamente apta para el pastoreo de ganado bovino, equino y ovino en unidades productivas basadas en derechos individuales de propiedad, denominadas "estancias". La agricultura de cereales encontraba un desarrollo adecuado al tamaño del mercado y a las condiciones tecnológicas de la época, en unidades productivas denominadas "chacras". En unas y otras la mano de obra familiar jugaba un papel fundamental, junto al trabajo esclavo, y en menor importancia, el asalariado. Un estudio de la composición de la mano de obra en las unidades productivas rurales del espacio montevideano mostró que, cerca de 1770 , cerca del $70 \%$ de la mano de obra empleada era de origen familiar (Moraes 2012). El acceso a la tierra, el ganado y las aguadas estaba generalizado mediante diversos mecanismos que no resultaban excluyentes entre sí: las donaciones reales, la compra o arriendo en el mercado, y la apropiación sin títulos eran formas alternativas y complementarias de acceder a los recursos (Moraes 2012). Así, una frontera agrícola abierta y una escasez relativa de brazos eran las notas distintivas del mercado de trabajo asalariado.

Existen numerosos indicios de que los mercados de trabajo urbano y rural estaban entrelazados. Del lado de la oferta, la actividad agrícola siempre disputó mano de obra a los otros sectores de actividad. En 1742 el director de las obras de fortificación de la ciudad de Montevideo se lamentaba en carta dirigida al Gobernador del Río de la Plata: "de los pocos peones que hice presente a VS el día trece, sólo han quedado los presos, con algunos conchabados y voluntarios porque los más de éstos se han escapado a la siega"7. Para retener a los trabajadores era común que los empleadores ofrecieran, además del salario monetario, beneficios adicionales como una ración de alimentos, el alojamiento y la yerba mate. Las autoridades políticas y administrativas podían recurrir a diversas formas de trabajo forzado,

\footnotetext{
${ }^{7}$ Citado en (Luque Azcona, 2003: 5).
} 
especialmente de presidiarios traídos del presidio de Buenos Aires, y de la propia ciudad ${ }^{8}$.

En el registro de trabajadores que construyeron la muralla de Montevideo existe constancia de la presencia de presidiarios en el personal empleado, pero no es posible determinar su participación en el total de ocupados porque la fuente no registra su nombre, si no apenas su condición. Los presidiarios actuaban tanto como peones no cualificados, como en calidad de herreros y carpinteros. Recibían una paga insignificante de 1 real por mes, que más que un salario parece una gratificación simbólica. En las estancias del rey también se encuentran registros esporádicos de "peón preso voluntario" y "peón preso voluntario extra".

Los indios de las misiones religiosas eran el otro recurso habitual de los empleadores públicos. Ha sido ampliamente documentado que en el Río de la Plata los indios de las misiones regidas por la Compañía de Jesús eran un contingente abundante y disciplinado de mano de obra, que la Corona solía movilizar cada vez que se enfrentaba a obras de grandes proporciones, como la construcción de la muralla de Montevideo (Furlong 1933; Assunçao 1978; Maeder 1992; Luque Azcona 2003). Las fuentes han permitido identificar numerosas cuadrillas de indios misioneros entre los ocupados en esa obra, reconocibles por estar registrados por nombres como Francisco Javier (sin apellido), Ramón Cambé, Diego Yapeyú, Antonio San Borja, Luis Tape. Figuran como "peones voluntarios" y reciben un salario insignificante, que en 1761 era de 6 reales mensuales. Las cartas-cuenta de la Caja Real aclaran que ese importe es una gratificación "para que compren hilo, jabón y otras menudencias necesarias a su aseo"; reciben también una libra y media de leña por día.

Además de los indios misioneros, llegaban a Montevideo indios no reducidos enviados desde Buenos Aires. Un documento de 1774 muestra que el Gobernador le enviaba al gobernador de Montevideo desde la capital un cacique y veinte indios destinados a trabajar en las obras de fortificación ${ }^{9}$. Los registros contables comentados en el apartado 2 muestran que en 1759 trabajan como "peones voluntarios" un individuo identificado como "Asensio el indio", un "Javier Pampa" y un "Ignacio Pampa", con remuneraciones mensuales de entre 4 y 6 pesos $^{10}$.

Finalmente, se sabe que tanto en Buenos Aires como en Montevideo los esclavos a menudo eran empleados por sus amos en las más diversas

${ }^{8}$ Las remisiones como trabajadores para las Real Obras de individuos que cometían alguna falta o delito comenzaron ya en 1746. En 1764 el Gobernador Pedro de Cevallos remitió desde Buenos Aires 15 presos para trabajar en las Reales Obras, y en julio de 1773, de acuerdo a una "relación del vestuario distribuido a los Presidiarios de las Reales Obras de fortificación", había 129 presos trabajando a los que se les entregó "chaleco, calzones, dos camisas y un gorro". AGN, AGA, Caja 1, carpeta 24; Caja 12, carpeta 7 y Caja 30, carpeta 8.

9 AGN, AGA, Caja 37, carpeta 6, 1774.

10 De modo genérico eran llamados "indios pampas" los de la orilla sur del Río de la Plata. 
actividades productivas de la ciudad. Sus propietarios los empleaban en determinadas tareas al servicio de terceros a cambio de una paga cuya porción mayor quedaba en manos del amo (Thul 2013). Esta situación aparece en caso del personal de las estancias del rey, donde figura un "esclavo conchabado".

El trabajo asalariado verdaderamente libre de la región, es decir el que no estaba sometido a formas no económicas de coerción, se caracterizaba por la inestabilidad de la permanencia en el empleo. Para el caso de Buenos Aires en el período virreinal (1776-1810), se ha dicho que "suponer la existencia de un empleo continuo, regular con salario constante tergiversa de manera burda las experiencias de empleo claramente indicadas en la documentación" (Johnson 1990).

Un factor de inestabilidad adicional venía dado por la estacionalidad de la demanda, que típicamente es muy marcada en el sector de la construcción y en las actividades rurales. Un estudio específico sobre las obras de la reconstrucción de la Iglesia Matriz mostró la alta rotación de los peones. A modo de ejemplo, en 1799 se contrataron 72 individuos diferentes como peones, pero mientras que algunos trabajaron sólo durante un mes, otros lo hicieron todo el año. Un simple ejercicio permitió mostrar que el total de jornales pagados al cabo del año se podían haber cubierto con el trabajo permanente de 19 trabajadores empleados, si cada uno de ellos hubiera trabajado durante 25 días entre enero y diciembre. Pero contratar 19 trabajadores de forma constante no era conveniente para los financiadores de la obra, porque durante los meses de invierno no eran necesarios más que 8 y en el resto del año se precisaban mucho más que 20. (Thul 2015). De manera predominante las fuentes empleadas en este trabajo presentan registros de remuneraciones mensuales para la amplia mayoría de las categorías ocupacionales, sean cualificadas o no cualificadas. Son escasos, dispersos y difíciles de interpretar los registros del pago de jornales, puesto que parecen referirse siempre a personas que trabajaron muy pocos días, cualquiera fuera su oficio, y muchas veces, por una paga mayor que sus pares de presencia regular en la nómina, como si hubieran sido contratados para resolver una necesidad circunstancial.

Al parecer, algunos trabajadores eran contratados mensualmente, otros semanalmente y otros por jornal, según las necesidades de la actividad. No existían los contratos escritos y las condiciones de contratación eran acordadas de palabra entre el trabajador y el empleador. Era frecuente la presencia de un componente no monetario en el salario, bajo la forma de una ración de alimentos en algunos casos, y en otros casos de yerba y tabaco. Entre los asalariados de la Real Hacienda no era infrecuente que la ración estuviera monetizada, de tal modo que, en vez de recibirla en especie, los asalariados recibían un complemento monetario por concepto de ración. Por ejemplo, los marineros y patrones de barcos de la vigilancia costera recibieron entre 1786-1789 este complemento monetario por concepto de ración en un renglón aparte de su salario, pero a partir de 1795 el importe 
fue incorporado al salario, que desde ese año recibe la aclaración "inclusa la ración" ${ }^{11}$.

El aumento del salario nominal en algunos casos era iniciativa del empleador, de acuerdo a su apreciación del rendimiento del empleado. En 1774 el ingeniero a cargo de la obra de la fortificación de Montevideo escribió al oficial de la Real Hacienda en Montevideo pidiendo un aumento de sueldo para dos esclavos conchabados:

"habiendo reconocido la aplicación y la habilidad de los negros llamados Francisco Elizegui y Pedro Urcola, que se han distinguido en catorce meses que los he experimentado, habiendo trabajado dos meses de balde, se les ha adjudicado, después, doce pesos mensuales, y como los hallo ahora merecedores de mayor premio, lo represento a VM. para que de común acuerdo[...] se les asigne veinte pesos a cada uno mensuales"12.

La iniciativa patronal podía ir en dirección contraria y causar una rebaja del salario nominal, situación que no era aceptada pasivamente por los afectados. En 1792 una docena de carpinteros y catorce calafates de la maestranza del puerto, protestaron ante una rebaja en sus jornales dispuesta por sus superiores, violando lo que consideraban cierta "inconcusa práctica y costumbre casi inmemorial"13.

En otros casos eran los asalariados quienes tenían la iniciativa y tenía lugar un proceso de negociación. En 1775, los operarios empleados en las Reales Obras acudieron "todos en común"- al Comandante del fuerte de Santa Teresa para expresar sus reclamos salariales:

"habiendo venido a trabajar ajustados mensualmente cada individuo por el sueldo que han conocido (...) en cuya contrata han continuado y continuaran hasta su limitado tipo, dicen que viendo la falta de carbón (por cuya causa se dilata el trabajo) como así mismo los malos temporales que ocurren, solicitan saber si incurren en la desquita de sus sueldos y siendo asi: suplican a vuestra merced se sirva manifestar si le parece conveniente para en su defecto ocurrir a V.S a fin de que nos haga la Justicia que en este asunto se requiere"14.

La respuesta de comandante, escrita al margen de la solicitud, establece que "el Rey no deberá pagar a los suplicantes los días que no trabajen por falta de carbón", y opinó que eran los propios trabajadores quienes debían acopiar el carbón para evitar dilaciones.

\footnotetext{
11 AGI, Buenos Aires 448.

12 AGN (Uruguay), AGA, Caja 37, carpeta 9, 1774.

13 (Bentancur 1997), p. 215.

14 AGN (Uruguay), AGA, Caja 38, carpeta 10, 1775.
} 


\section{NIVEL Y EVOLUCIÓN DE LOS SALARIOS NOMINALES}

El Cuadro 1 muestra la evolución del salario nominal para un conjunto de categorías ocupacionales cualificadas y no cualificadas de diversos sectores de actividad. En la estimación fueron dejados de lado los peones "presos voluntarios", y cuando fue posible identificarlas de manera fidedigna, las cuadrillas de indios misioneros enrolados en las obras públicas. Para adecuar la información a los requerimientos de la estimación del ratio de bienestar, las remuneraciones mensuales fueron convertidas a diarias con el supuesto de un mes de 21 días laborables ${ }^{15}$. Los jornales diarios así obtenidos fueron confrontados con los escasos datos diarios registrados en las fuentes, para comprobar que sus niveles no diferían significativamente. En particular se empleó un registro de 1796-1802 que corresponde a la construcción del Hospital de Caridad, cuyo detalle del primer año mencionado permite ver con claridad los niveles y la escala de jornales del personal de la construcción en 1796. Esa fuente muestra que el jornal de los peones corre, en ese año, en un amplio rango de 2 a 5 reales, pero la mayoría abrumadora de los peones recibía un jornal de entre 3 y 4 reales por día, cifra que coincide con lo que se muestra en el Cuadro $1^{16}$.

Aunque este trabajo no presenta una comparación exhaustiva con otras ciudades hispanoamericanas en relación con esta variable, hay indicios de que el nivel de los salarios nominales de Montevideo era, en términos generales, alto. Un albañil montevideano contratado por mes ganaba c. 1800 entre 11 y 12 pesos, es decir lo mismo que un albañil de la capital virreinal Buenos Aires en 1810 (Gelman y Santilli 2015) y algo más del doble que los peones y albañiles de Santa Fe (Gelman y Santilli 2015).

El Cuadro 1 muestra que los jornales nominales registraron fluctuaciones de diverso tenor entre 1760-1810. Entre los cualificados se observa una tendencia generalizada al alza, en casi todos los casos a partir de 1780. Entre los no cualificados el panorama es menos claro, ya que los oficiales albañiles permanecieron invariables y los peones de estancia experimentaron un ligero descenso.

La remuneración del personal empleado en la construcción (columnas 3 , 4, 5, 7 y 10 del cuadro) muestra una clara graduación entre categorías ocupacionales. Las remuneraciones más bajas son las percibidas por los peones; los siguen los capataces, ligeramente por encima de los oficiales albañiles. Los carpinteros y el sobrestante de las obras de fortificación de la ciudad percibían los salarios más altos del sector. Esta misma situación se repite entre el personal ocupado en la vigilancia costera (columnas 1 y 8 ), donde

15 La evidencia disponible por el momento para Montevideo no permite hacer hipótesis firmes sobre la cantidad de días trabajados por mes. A cuenta de futuras estimaciones mejor fundadas, se llega a este número tomando en cuenta cuatro domingos por mes, y entre 5 y 6 días adicionales por concepto de otras conmemoraciones religiosas del calendario católico, así como contratiempos climáticos.

16 Archivo General de la Nación (Uruguay); AGA, Libro 689. 
CUADRO 1

REMUNERACIONES DIARIAS (EN REALES) DE TRABAJADORES CUALIFICADOS Y NO CUALIFICADOS, MONTEVIDEO 1760-1810, PROMEDIOS DECENALES

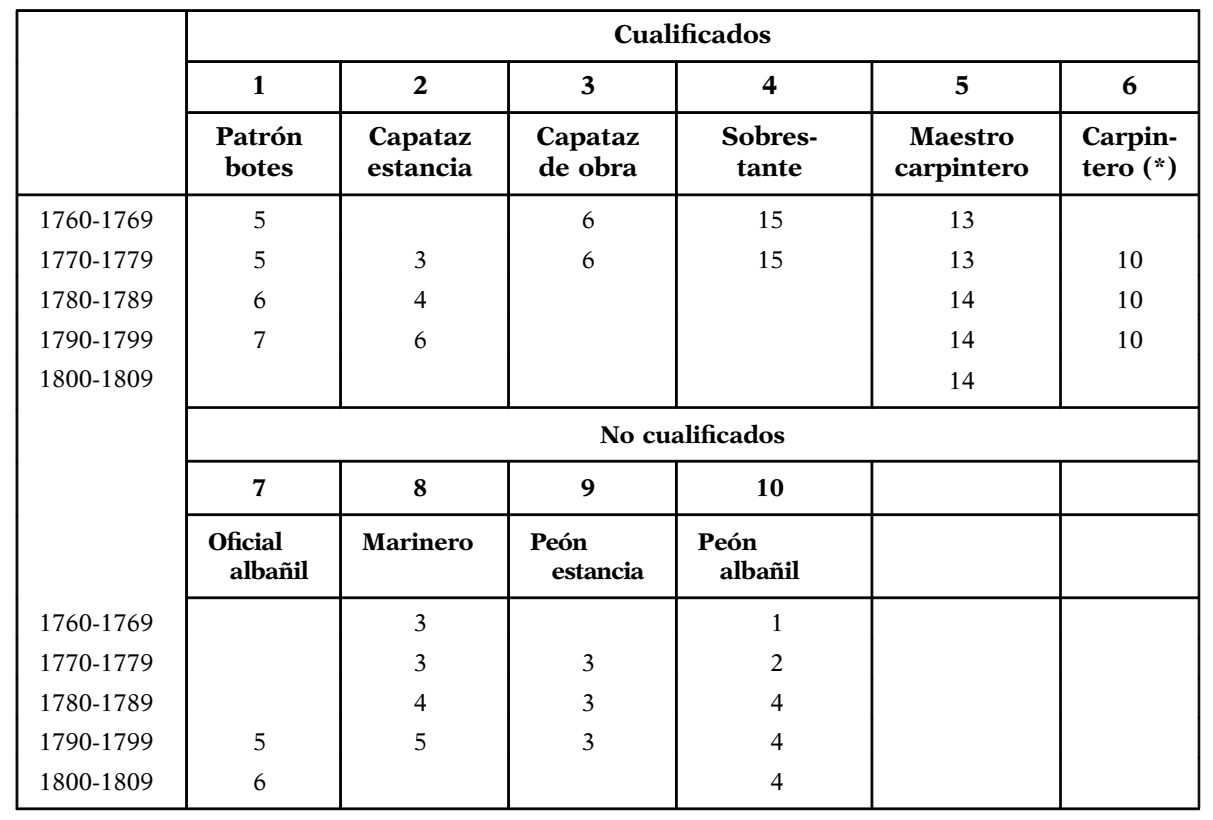

Fuentes: Columnas 1, 2, 6, 8 y 9: Archivo General de Indias (España), Buenos Aires, 445-446 y 448 y Archivo General de la Nación (Uruguay), AGA, Libro 161. Columnas 3, 4, 5,7 y 10: Archivo General de la Nación (Argentina), Sala IX, 03-02-05, División Colonia, Sección Gobierno Montevideo, Iglesia Matriz, Cuentas, 1781-1808. Archivo General de la Nación, (Uruguay), Archivo General Administrativo, Cajas cronológicas, 1758-1800, $\mathrm{N}^{\circ} 25,30,37,48,51,55,72,85,88,94,99,106,109,116,118,122,125,128,140$, $145,154,157,190,221,234,235,243,258,274,282,319,322,328,334$.

(*) "carpintero del Rey" empleado en el mantenimiento de las carretas del ejército.

también puede apreciarse una jerarquía de remuneraciones acorde a la función de cada cargo.

Los salarios de la estancia real de Montevideo presentan algunas singularidades. Hasta 1784 el capataz de la estancia tuvo una remuneración mensual menor que el peón común, situación que puede atribuirse al hecho de que el capataz era frecuentemente un militar que recibía una paga como tal, al margen de su función en la estancia del Rey. Otra posibilidad es que la remuneración del capataz se viera complementada con alguna clase de participación en el producto de la estancia, o de acceso a recursos productivos para beneficio propio De hecho, la aparcería en sus diversas formas era un recurso frecuente para estabilizar personal en la economía agropecuaria pre-moderna.

También, es posible que esa aparente anomalía reflejara una dificultad para conseguir personal no ligado (en este caso concreto) al cuerpo militar y 
CUADRO 2

PREMIO POR CUALIFICACIÓN POR GRUPO DE OCUPACIONES (PROMEDIO POR DÉCADA)

\begin{tabular}{|l|c|c|c|c|c|c|}
\hline & & & \multicolumn{4}{|c|}{ Construcción } \\
\cline { 4 - 7 } & $\begin{array}{c}\text { Vigilancia } \\
\text { costera }\end{array}$ & Rurales & $\begin{array}{c}\text { Capataz/ } \\
\text { peón }\end{array}$ & $\begin{array}{c}\text { Maestro } \\
\text { carpintero/ } \\
\text { carpintero } \\
\text { de carretas }\end{array}$ & $\begin{array}{c}\text { Sobres- } \\
\text { tante/ } \\
\text { peón } \\
\text { albañil }\end{array}$ & $\begin{array}{c}\text { Oficial } \\
\text { albañil/ } \\
\text { peón } \\
\text { albañil }\end{array}$ \\
\hline $1760-1769$ & 1.5 & & & & & \\
$1770-1779$ & 1.5 & 0.9 & 4.5 & 1.4 & 11 & \\
$1780-1789$ & 1.5 & 1 & 3 & 1 & 8 & \\
$1790-1799$ & 1.5 & 1.7 & & 1 & & 1.2 \\
$1800-1809$ & & & & & & 1.3 \\
\hline
\end{tabular}

Fuente: En base a datos del Cuadro 1. El número en cada celda expresa la cantidad de veces que el salario cualificado contiene al no cualificado.

por lo tanto con posibilidades reales de rehusarse al desempeño del cargo. Si fuera el caso, se estaría ante una confirmación más de la elevada rotación del personal de los establecimientos ganaderos rioplatenses del período colonial que ya ha sido señalada por otros autores (Mayo 1987; Amaral 1987). Sólo cuando en 1784 el antiguo capataz dejó su cargo la estancia del Rey contrató (tras dos años de vacancia que quizás revelen la dificultad para conseguir sustituto) un nuevo capataz con una remuneración mayor que la de sus subordinados. En relación a la figura del "peón común” de la estancia, cabe anotar que la fuente aclara que el salario mensual lleva "inclusa la ración”, la cual también en este caso como en el ya mencionado de los marineros, evidentemente ha sido monetizada e integrada al salario.

El Cuadro 2 permite apreciar mejor el diferencial salarial entre cualificados y no cualificados. En la mayoría de los casos el premio por la cualificación va de 0.9 a 1.5 , con excepción del capataz de obra y sus peones, y el de los sobrestantes de obra y sus peones durante todo el período. Es posible que el sobrestante de las obras de fortificación de Montevideo fuera un cargo de confianza político-militar y eso explique tanto su elevada remuneración como el asombroso diferencial salarial que marca su relación con el peón de la obra. En cambio, el elevado diferencial entre el capataz de la obra y sus peones podría estar revelando la necesidad de pagar muy bien a los capataces para estabilizarlos en sus cargos. En todos los casos se trata de premios sumamente elevados, no sólo en relación con las áreas del centro y norte de Europa en la segunda mitad del siglo XVIII, sino en relación con Madrid (Llopis y Montero 2011) y ciudades del este europeo en la misma época (Van Zanden 2009). Por cierto, una estimación del nivel y la evolución del capital humano de la fuerza laboral de Montevideo entre la mitad del siglo XVIII y los inicios de la Primera Globalización mostró que los niveles 
de capital humano en la ciudad rioplatense eran aún más bajos que los de las ciudades sur-europeas en todo el período (Vicario 2015). Si bien hasta cierto punto parece lógico que, en una ciudad caracterizada por la escasez de trabajo y la escasa dotación de capital humano de la población activa en general, los escasos operarios más cualificados encontrasen remuneraciones sustantivamente superiores, los aspectos institucionales vinculados a la formación del capital humano que pudieran agravar esta situación merecen posterior investigación.

\section{PODER DE COMPRA DEL SALARIO Y NIVELES DE BIENESTAR}

Para adaptar el patrón de consumo de alimentos que refleja la cesta europea de supervivencia comentada en el apartado 2 a la realidad de la jurisdicción montevideana, se buscó tener una idea aproximada de las pautas alimenticias de la población en el período. Un punto de partida se encuentra en la normativa de la Real Armada española, según la cual los hombres embarcados debían recibir, de lunes a viernes, ciertos suministros para su alimentación en cantidades fijas.

El pan, el agua y el vino debían dispensarse todos los días; las legumbres (concretamente garbanzos y/o arroz) debían recibirse una vez por semana, el tocino también una vez por semana, el pescado seco dos veces por semana, y la carne salada dos veces por semana. Además los hombres debían recibir sal, aceite y leña para cocinar (Sandrín 2013). Esta lista refleja el tipo y la cantidad de provisiones que la Real Armada entendía debían recibir unos varones adultos y sanos, para estar en condiciones óptimas durante el servicio.

En la realidad del Río de la Plata la cesta de provisiones proporcionadas a los marinos era un poco menos variada. Los contratos firmados por los abastecedores de la Real Armada entre 1770 y 1810 estipulaban que los marinos apostados en el puerto de Montevideo debían recibir de sus abastecedores una ración diaria conformada por unas cantidades fijas de pan (o bizcocho en su defecto), carne vacuna fresca, una porción de legumbres y leña (Sandrín 2013). Las cantidades estipuladas en esos contratos muestran que los componentes principales de la dieta, desde el punto de vista de su aporte en calorías, eran claramente la carne y el pan. La cesta de consumo que surge de estos contratos puede verse en el Cuadro 3. Es destacable que, de acuerdo a esta información, las provisiones diarias estipuladas en estos contratos garantizarían a los marinos de la Real Armada apostados en Montevideo una ingesta calórica cercana a las 3000 calorías diarias, una cifra acorde a los estándares establecidos actualmente por la Organización Mundial de la Salud para varones adultos.

La carne, el pan y las legumbres, parecen haber formado una "trinidad" alimentaria regional, apenas acompañada de sal y ají. La importancia del 
CUADRO 3

CESTA BÁSICA DE CONSUMO DE LOS MARINOS DE LA REAL ARMADA EN MONTEVIDEO, 1770-1810

\begin{tabular}{|l|c|c|c|c|c|}
\hline & $\mathbf{1}$ & $\mathbf{2}$ & $\mathbf{3}$ & $\mathbf{4}$ & $\mathbf{5}$ \\
\cline { 2 - 6 } & $\begin{array}{c}\text { Cantidades } \\
\text { diarias } \\
\text { (en kilos) }\end{array}$ & $\begin{array}{c}\text { Calorías/ } \\
\text { día }\end{array}$ & $\begin{array}{c}\text { Proteínas/ } \\
\text { día }\end{array}$ & $\begin{array}{c}\text { Calorías } \\
\mathbf{( \% )}\end{array}$ & $\begin{array}{c}\text { Proteínas } \\
\mathbf{( \% )}\end{array}$ \\
\hline Pan & 0.680 & 1667 & 56 & 56.9 & 31.9 \\
Carne & 0.500 & 1250 & 100 & 42.7 & 64.2 \\
Legumbres & 0.086 & 13 & 6 & 0.5 & 0 \\
Sal & 0.028 & & & 0 & 0 \\
Ají & 0.014 & & & 0 & 0 \\
Leña & 0.689 & & 162 & 100 & - \\
Totales & & 2930 & & & 100 \\
\hline
\end{tabular}

Fuentes: Columna 1: Cantidades estipuladas en los contratos firmados entre 1770-1810 (Sandrín, 2014: 96). Dado que la fuente hace referencia a "raciones" de carne sin precisar su peso, la cantidad de carne diaria se obtuvo con el supuesto (conservador) de que los marinos recibían una ración de 3,45 $\mathrm{Kg}$ cada 7 días. El peso de la ración se calculó como la sexagésima parte de una res en canal. El peso de la res en canal se tomó de (Garavaglia 1999: 243). La conversión a kilogramos se hizo con las equivalencias establecidas en "Colonial Latin American metrology", en: www.gpih.ucdavis.edu. Columnas 2, 3, 4 y 5: Con los mismos contenidos calóricos de los alimentos establecidos en Allen (2001). El ají y la sal fueron excluidos del cálculo porque su impacto en el total resultaba insignificante.

consumo de carne y pan en el Río de la Plata ha sido ampliamente documentada para la región; por otro lado, el pan y diversos tipos de legumbres formaban parte de la lista de alimentos cuyos precios eran controlados por el cabildo de Montevideo mediante una tarifa de publicación cuatrimestral (Moraes y Thul 2015).

Para adaptar la cesta de consumo de supervivencia europea al caso montevideano se modificaron tanto la lista de bienes como las cantidades. La modificación de la lista tuvo como objetivo adaptar la estructura del consumo de alimentos y bebidas a la oferta y los hábitos locales. Así, el pan, la carne y las legumbres fueron considerados alimentos básicos, encargados de suministrar el grueso de las calorías diarias. A ellos se agregó el vino, como equivalente local del consumo de cerveza que incluye la cesta europea propuesta en Allen (2001). La modificación de las cantidades de alimentos y alcohol consumidas por día tuvo como objetivo reducir la ingesta calórica hasta el nivel de subsistencia (1941 kcal por día) establecido en la cesta europea. Únicamente por este motivo se aceptó un consumo diario de carne que es notoriamente menor que el sugerido por todas las estimaciones disponibles para el Río de la Plata. El Cuadro 4 muestra la cesta propuesta.

Para representar el consumo de textiles se eligió el lienzo de algodón de origen misionero, de amplia circulación en el Litoral rioplatense y para el 
CUADRO 4

VERSIÓN LOCAL DE LA CESTA EUROPEA DE 1.941 CALORÍAS, C. 1760-1810

\begin{tabular}{|c|c|c|c|c|c|c|}
\hline & 1 & 2 & 3 & 4 & 5 & (A) \\
\hline & Cantidades diarias & Calorías/día & Porcentaje & Proteínas/día & Porcentaje & $\begin{array}{l}\text { Proporción } \\
\text { del gasto total }\end{array}$ \\
\hline Pan & 498 gr. & 1220 & 62.9 & 50 & 55.7 & 47.4 \\
\hline Legumbres & 50 gr. & 56.3 & 2.9 & 3.6 & 4 & 12.9 \\
\hline Carne & $180 \mathrm{gr}$. & 450 & 23.2 & 36 & 40.3 & 0.8 \\
\hline Vino & $0.252 \mathrm{lt}$ & 214.2 & 11 & & 0 & 13.8 \\
\hline Total alimentos & & 1941 & 100 & 89 & 100 & 74.8 \\
\hline & \multicolumn{5}{|c|}{6} & \\
\hline & \multicolumn{5}{|c|}{ Cantidades anuales } & \\
\hline Lienzo de algodón & \multicolumn{5}{|c|}{5 metros } & 5 \\
\hline Leña & \multicolumn{5}{|c|}{$280 \mathrm{~kg}(*)$} & 16.5 \\
\hline Jabón & \multicolumn{5}{|c|}{$2,6 \mathrm{~kg}$} & 3.5 \\
\hline Velas & \multicolumn{5}{|c|}{$2,6 \mathrm{~kg}$} & \\
\hline $\begin{array}{c}\text { Aceite para } \\
\text { lámparas }\end{array}$ & \multicolumn{5}{|c|}{2,6 lt. } & \\
\hline
\end{tabular}

Fuente: Columna 1: cantidades de alimentos ajustadas para obtener 1.941 calorías diarias a partir del contenido calórico de la carne, el pan, las legumbres y le vino. Columnas 2, 3, 4, 5 y 6: Con base en las equivalencias empleadas en Allen (2001), excepto (*) que expresa la cantidad de kilos de leña necesarios para obtener 3 millones de BTU, equivalente al 60\% del consumo energético anual establecido en Allen (2001) para Europa central y del norte. Columna A: Porcentaje del costo total de la cesta, estimado a precios promedio de todo el período. 
combustible se eligió la leña. Las cantidades asignadas al consumo de textiles, así como a jabón, velas y aceite se dejaron idénticos a los de la cesta europea. Siguiendo a Djenderedjian y Martirén (2015) sobre el caso de la cercana ciudad de Santa Fe, se redujo la cantidad de BTU de 5 a 3, teniendo en cuenta que las temperaturas medias en Montevideo son más altas que las de Europa central y del norte ${ }^{17}$. Para tener en cuenta el gasto en vivienda así como el tamaño familiar, se siguió el mismo criterio de escalar el costo de la cesta de consumo usando un factor, que en este caso se fijó en 3, en vez del 3.15 establecido en Allen (2001). Desde luego, la cuestión del tamaño familiar es crucial en estas estimaciones, pero para el caso montevideano no se tienen más que apreciaciones dispersas sobre las estrategias empleadas por las familias de los trabajadores manuales para resolver su alojamiento, y todavía no se dispone de estimaciones precisas sobre el tamaño familiar para este período.

Así, en este trabajo se adopta un multiplicador de menor tamaño para hacer lugar a la hipótesis de que, debido al alto índice de masculinidad que caracteriza a la población de Montevideo, la tasa de dependencia fuera menor que la de las ciudades europeas analizadas en Allen (2001).

El costo de la cesta se estimó empleando un conjunto de series de precios cuyo análisis pormenorizado se presenta en otro trabajo (Moraes y Thul 2015). A los efectos de este estudio, corresponde señalar que la serie del precio del pan recoge una estimación realizada en base a los precios publicados por el Cabildo de Montevideo y los precios del trigo entre 17601810. La serie del precio de la carne recoge una estimación realizada a partir del precio de la res en canal pagado para el abasto de los presos de la ciudad entre 1780-1810, y el precio del novillo en pie que surge de los inventarios post-mortem de propiedades rurales de la campaña montevideana entre 1760-1810. Las series del vino y las legumbres fueron construidas a partir de las listas de precios publicados por el cabildo de Montevideo; los niveles y fluctuaciones de estas series fueron controladas por las reportadas para los mismos bienes en Buenos Aires para los mismos años, en base a registros contables de instituciones religiosas. El precio del lienzo misionero fue recogido de los libros contables del almacén comercial de los pueblos misioneros en Buenos Aires, desde donde el producto se distribuía a todo el espacio rioplatense. Por carecer de datos locales, para la leña se usó el precio de ese bien en Buenos Aires en el período ${ }^{18}$. Debido a que fue imposible determinar el precio por unidad de medida del jabón, las velas y el aceite para lámparas, se aumentó un 3.5\% del gasto en alimentos y bebidas por este concepto. Se trata de un porcentaje significativamente menor que el

17 Para la vecina ciudad de Buenos Aires ha sido propuesta un consumo anual de 2,5 BTU en (Arroyo-Abad, Davies, y van Zanden 2012). Se asume que a los efectos de esta primera aproximación a la tasa de bienestar, la diferencia entre una y otra cantidad de BTU no tiene impactos significativos.

18 Según www.gpih.ucdavis.edu. Los datos allí recogidos surgen de las compras del convento de San Pedro Telmo de la ciudad de Buenos Aires. 
acordado a este rubro en Allen (2001), bajo el supuesto de que el precio de la materia prima de los dos primeros (grasa animal) debió haber sido más barata en esta economía ganadera que en la Europa de la segunda mitad del siglo XVIII.

La estructura del gasto que expresa la columna A del Cuadro 4 refleja el alto peso de la alimentación en la cesta del asalariado, y el alto peso del pan entre los alimentos. En contraste, la escasa incidencia de la carne en el gasto individual sólo parcialmente refleja una estructura realista del consumo, puesto que resulta de haber asignado artificialmente un consumo de carne muy bajo, pero también de unos precios ínfimos de la carne en el espacio estudiado. Mientras que lo primero es consecuencia de una decisión metodológica deliberada que busca respetar el máximo de calorías diarias de la cesta europea, lo segundo es resultado de la abundancia de la oferta de carne que caracterizaba la región rioplatense. Si se ajustaran los volúmenes de carne a cantidades más realistas es probable que la carne tuviera un peso algo mayor en la estructura del gasto, pero difícilmente mucho más alto; a modo de ejemplo, una estimación del consumo de los asalariados de Buenos Aires entre 1777-1810 situaba en un 5\% el peso de la carne en el gasto total (Johnson 1992).

El Cuadro 5 muestra la ratio de bienestar (RB) obtenida para trabajadores montevideanos entre 1760-1810. Se calculó la ratio de bienestar de los asalariados libres de Montevideo para las 10 categorías ocupacionales presentadas en el Cuadro 1, con el criterio de que representan adecuadamente la remuneración de los sectores subalternos de asalariados libres, tanto los que pueden considerarse no cualificados (grupo 1) como aquellos de cierta cualificación (grupo 2). Las remuneraciones diarias del cuadro 1 fueron empleadas para estimar el ingreso anual de cada categoría ocupacional bajo el supuesto de 250 jornadas de trabajo por año generalizado a partir de Allen (2001). No se conocen estimaciones específicas para el caso de Montevideo en esta materia; se ha mantenido el supuesto de 250 días con fines comparativos y a cuenta de hipótesis mejor fundadas, que solo la investigación futura podrá sugerir.

La ratio de bienestar (RB) permite discriminar claramente dos tipos de situaciones. En el grupo 1 están aquellas ocupaciones que al menos en algún momento del período 1760-1810 alcanzan una RB igual o mayor a 1, y en el grupo 2 aquellas que no alcanzan a 1 en ninguna década.

Es notorio que el grupo 1, formado por quienes alcanzan el nivel de supervivencia, constituye un conjunto de ocupaciones caracterizado, en algunos casos, por niveles de cualificación relativamente altos (caso del maestro carpintero) y en otros casos por ser cargos de confianza (caso del sobrestante de las reales obras). Si se deja de lado el patrón de botes antes de 1780, puede decirse que los trabajadores montevideanos del grupo 1 presentan, durante la segunda mitad del siglo XVIII, niveles de bienestar similares a los reportados en (Allen 2001) para el personal de la construcción en Londres en la misma época. 
CUADRO 5

RATIO DE BIENESTAR (RB) DE DIVERSAS CATEGORÍAS OCUPACIONALES EN LA JURISDICCIÓN DE MONTEVIDEO, 1760-1810

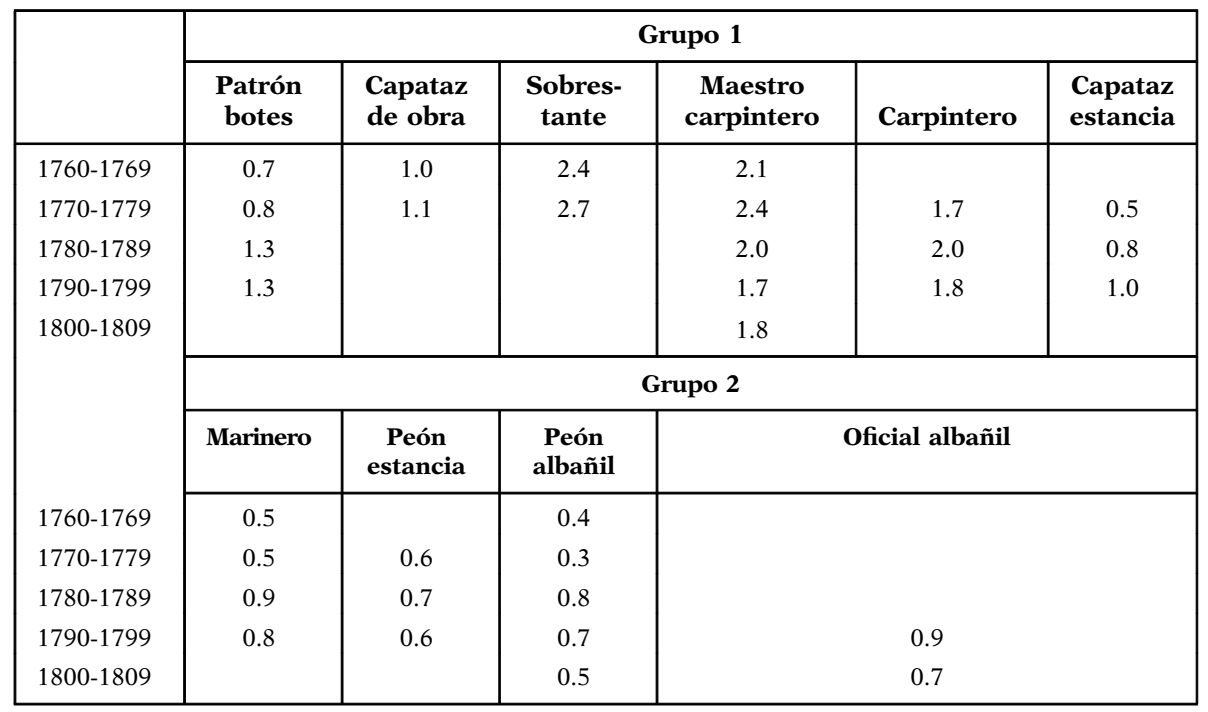

Fuentes: calculado sobre la base de promedios decenales de salarios nominales del Cuadro 1 y la cesta del Cuadro 4. La conversión de pesos corrientes a gramos de plata se hizo según las equivalencias establecidas en www.gpih.ucdavis.edu.

El grupo 2 está formado por un conjunto heterogéneo de ocupaciones, algunas rurales y otras urbanas, con niveles diversos de cualificación, pero en conjunto menores que los del grupo 1. En términos generales puede decirse que estas categorías ocupacionales aproximan un segmento importante de los sectores subalternos de la sociedad colonial, ya que si bien no incluye los esclavos ni los indios entonces denominados "infieles", se trata de las personas que se ocupan en tareas sencillas de sectores rurales (agro) y urbanos (construcción y puerto) de reconocida importancia en la estructura productiva local. De acuerdo a estos resultados, los trabajadores de los sectores subalternos estarían impedidos de acceder a una cesta de consumo que ha sido definida como una línea de pobreza. En contraste con el grupo 1, las ratios de bienestar de estas categorías ocupacionales son similares a las obtenidas para ciudades europeas de bajos salarios, como Milán y Viena (Challú y Gómez-Galvarriato 2015). En el apartado siguiente se analiza con detenimiento este resultado. Entretanto, es útil tener un panorama sobre la evolución del salario real en el tiempo.

El nivel de los salarios reales evolucionó de manera dispar entre 1760-1810, según las categorías ocupacionales. El Gráfico 1 muestra información sobre las únicas ocupaciones que presentan información sobre remuneraciones para todas las décadas analizadas en este estudio. Se trata de dos casos de especial interés, 


\section{GRÁFICO 1}

RATIO DE BIENESTAR DEL MAESTRO CARPINTERO Y DEL PEÓN DE LA CONSTRUCCIÓN, MONTEVIDEO 1760-1810

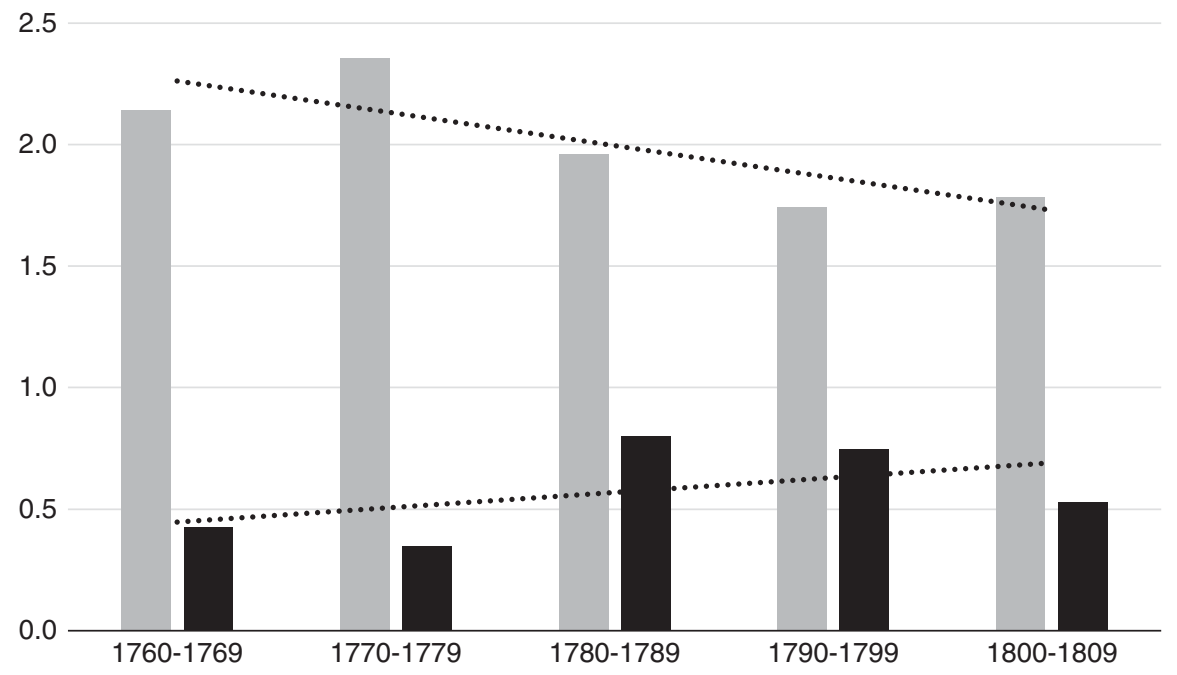

Fuente: Datos del Cuadro 5 y tendencias lineales

como son el maestro carpintero (oficio que, como se dijo antes, goza de altos premios por cualificación a lo largo del período) y el peón de la construcción, ocupación que ha sido ampliamente tomada como referencia en los estudios mencionados El gráfico muestra que el maestro carpintero experimentó un descenso de su salario real a partir de la década de 1780, mientras que el peón de la construcción habría experimentado una mejora tendencial, que sin embargo no esconde una caída entre la última década del siglo XVIII y la primera del siglo XIX. Futuras investigaciones deberán dilucidar en los factores comunes y diferentes que guiaron estos comportamientos.

Por el momento, se sabe que los precios de los alimentos en Montevideo experimentaron un marcado aumento entre 1796-1806 (Moraes y Thul 2015) y que procesos inflacionarios parecidos, tuvieron lugar en Buenos Aires (Jhonson y Tandeter 1992), Santa Fe (Djenderedjian y Martirén 2016) y Santiago de Chile (Llorca-Jaña y Navarrete-Montalvo 2015) entre los años finales del siglo XVIII y comienzos del siglo XIX.

\section{6, MONTEVIDEO EN EL CONTEXTO HISPANOAMERICANO}

El gráfico 2 presenta una comparación de la ratio de bienestar de Montevideo con la información disponible para otras ciudades latinoamericanas. 


\section{GRÁFICO 2}

RATIOS DE BIENESTAR DE OCUPACIONES NO CUALIFICADAS EN CIUDADES DE AMÉRICA HISPANA, C. 1800

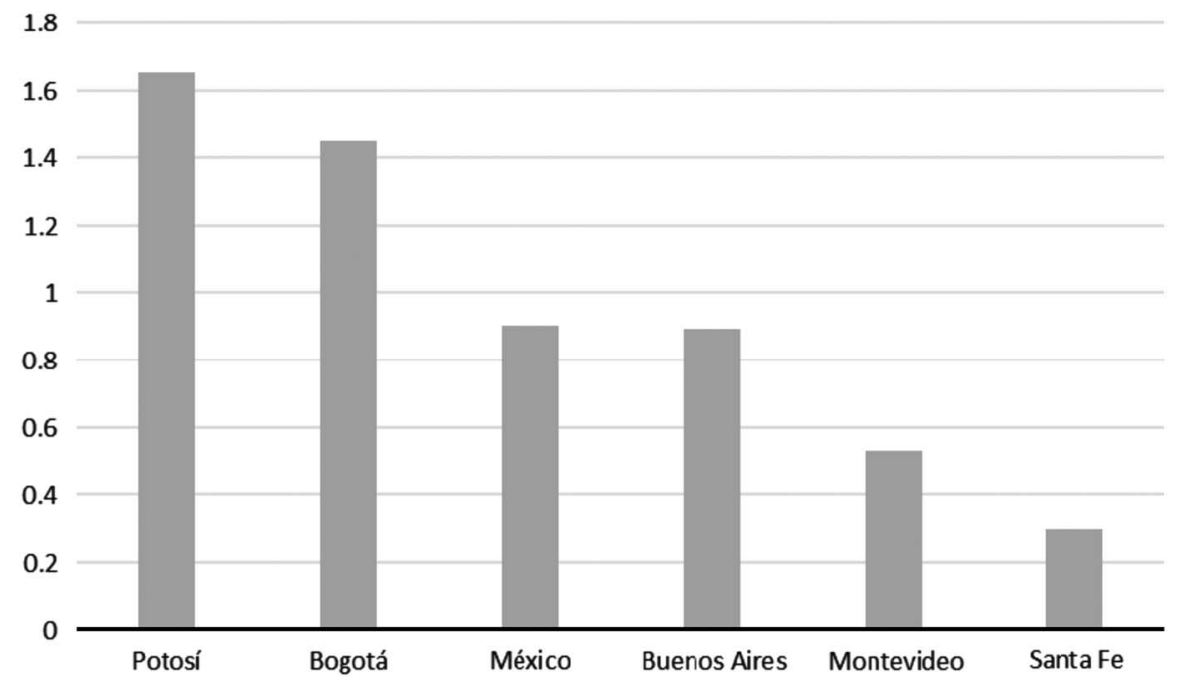

Fuentes: Potosí (1810) y Bogotá (1800) según (Arroyo Abad 2013); México (1800) según (Challú y Gómez-Galvarriato 2015), Buenos Aires (1810) según (Gelman y Santilli 2015). Montevideo (1800-1809) según datos del Cuadro 5; Santa Fe (1805) según la ratio de bienestar individual reportada en (Djenderedjian y Martirén 2015), escalada a un tamaño familiar de dos adultos y dos niños. Se agradece a estos autores, que generosamente facilitaron sus datos originales para hacer la operación.

Es notable que al comenzar el siglo XIX, de los casos representados en el gráfico , sólo Potosí y Bogotá presentan una RB mayor a la unidad, mientras que tanto en México como en las tres ciudades del Río de la Plata (Buenos Aires, Montevideo y Santa Fe), los trabajadores libres menos cualificados estarían por debajo del nivel de subsistencia.

Un caso diferente parece haber sido el de los trabajadores no cualificados de la construcción en Santiago de Chile, cuya ratio de bienestar en 1806 era de 1.4 (Llorca-Jaña y Navarrete-Montalvo 2015) ${ }^{19}$.

Una ratio de bienestar claramente por debajo de la unidad sugiere un panorama que contrasta, no sólo con la evidencia cuantitativa disponible sobre la ocurrencia de un notable proceso de expansión económica en ambas orillas del Río de la Plata durante esas décadas, sino con la información del acelerado crecimiento de la población de la jurisdicción de Montevideo entre

19 Las estimaciones para Santiago de Chile no se han incluido en este gráfico porque no ha sido publicado un cuadro con los resultados, sino un gráfico. 
1760-1810, que debe mucho al flujo de inmigrantes llegados de regiones americanas de antigua ocupación europea. Por lo demás, la magnitud y la frecuencia de las crisis de mortalidad de la jurisdicción de Montevideo no se comportan de manera dramática en este mismo período, particularmente en comparación con las crisis de mortalidad europeas, ni permiten suponer situaciones de hambruna frecuente entre los sectores menos favorecidos de la sociedad local (Pollero 2015). No sólo los más famosos cronistas europeos del período señalaron de modo recurrente la facilidad con que podían vivir y reproducirse en aquellos parajes los sectores sociales menos favorecidos (Azara 1943[1801]); también la historiografía económica reciente ha reconocido un "país de la abundancia" en el Litoral rioplatense (Fradkin y Garavaglia 2004).

Un comentario específico sobre las situaciones del capataz y el peón de estancia montevideanos puede arrojar luz sobre este asunto. En las ocupaciones rurales era habitual que el capataz de estancia tuviera acceso a recursos productivos propios como parte de su contrato, por cierto no escrito, de trabajo; frecuentemente tenía un rebaño propio que alimentaba con los pastos del empleador, o tenía parte en las ventas de productos de la estancia, donde por otra parte vivía sin pagar alojamiento. Por lo tanto, su incapacidad para cubrir con su salario monetario el costo de la supervivencia física de una hipotética familia de cuatro integrantes a lo largo de todo el período, más que una situación de pobreza extrema, muestra una situación donde el salario (monetario y no monetario) no es la única fuente de ingresos del asalariado, y tal vez ni siquiera la principal. En relación con el peón debe tenerse en cuenta que era habitual que este tipo de trabajador recibiera alojamiento, carne, pan y otros consumos básicos como salario no monetario, en unos volúmenes que podrían haber aligerado el gasto familiar de manera significativa. Por otro lado, no es improbable que ese peón rural fuera miembro de una familia campesina y que pasara parte del año ocupado en las tareas productivas de su núcleo productivo/familiar. De hecho, resultados recientes sugieren que el peón rural de Buenos Aires en 1810 tampoco alcanzaría a satisfacer el nivel de supervivencia con su salario (Gelman y Santilli 2015). No es impensable que, con matices, este tipo de consideraciones pudieran hacerse extensivas a otras categorías ocupacionales (marineros de la vigilancia costera, peones de la construcción) que no alcanzan el nivel de supervivencia en el caso de Montevideo. En efecto, se trata de economías donde las actividades rurales y urbanas están todavía estrechamente conectadas, donde los recursos son abundantes, la frontera agrícola está lejos de haber alcanzado su límite y existe una variedad de formas de acceso a los recursos productivos para amplios sectores de la población criolla y mestiza.

En definitiva, mirados en su contexto histórico preciso, estos resultados ponen una interrogante sobre el papel del ingreso salarial entre los trabajadores libres menos cualificados en economías como las del Río de la Plata 
antes de la independencia. Así, cobra vigor la hipótesis de que, tal como ha sido señalado por otros autores para espacios económicos similares de la región rioplatense, existe un conjunto significativo de los sectores populares para el cual el salario no constituye su principal fuente de ingresos (Djenderedjan y Martirén 2015).

\section{CONCLUSIONES}

En diversos contextos historiográficos los historiadores económicos se han interesado por conocer la evolución de los salarios reales de los trabajadores como una forma de conocer los cambios en el nivel de vida de la gente común. La estrategia de investigación que consiste en comparar la ratio de bienestar de una misma categoría ocupacional entre diversas regiones y períodos para hacer inferencias sobre los niveles de bienestar tiene atributos indiscutibles de sencillez y comparabilidad. Su aplicación a diversas ciudades del mundo ha permitido aumentar la evidencia empírica sobre salarios nominales, precios al consumo y salarios reales en todas partes donde se ha aplicado. En el caso específico de la región latinoamericana, ha permitido empezar a reducir la brecha entre la historiografía europea de precios y salarios para períodos pre-industriales y la de América Latina, que presentaba un considerable retraso. Sin embargo, los debates recientes sobre su aplicación al caso latinoamericano han hecho notar la importancia de poner especial atención a las condiciones específicas del trabajo asalariado en cada lugar, cuando se utilizan salarios reales para aproximar los niveles de bienestar.

Este trabajo empleó información de fuentes primarias para identificar y comentar algunas características del trabajo asalariado en el espacio económico de Montevideo durante la segunda mitad del siglo XVIII y la primera década del siglo XIX.

La evidencia confirma la intuición de que la oferta de trabajo era escasa en un espacio económico caracterizado por la muy baja densidad de población, la abundancia de recursos naturales y una trama institucional que permitía a amplios sectores de la población subalterna el acceso a pastos, ganados y aguadas mediante diversos arreglos.

Tanto los contratos de trabajo como el tipo y los niveles de remuneración reflejaron esta situación. Aquellos empleadores que, como la Real Hacienda, podían recurrir al trabajo forzado de presos y comunidades indígenas "reducidas", armaron sus plantillas de personal no cualificado con base en esos sectores. Los empleadores que no tenían acceso a ese recurso sufrieron una elevada rotación de sus peones y jornaleros. Para los cargos estables y de confianza se recurrió ampliamente al trabajo esclavo, así como al trabajo de soldados (en el caso de las obras reales). Los diferenciales salariales entre trabajadores cualificados y no cualificados eran importantes en todos los 
casos analizados y alcanzaban coeficientes muy altos entre los trabajadores de la construcción.

Los niveles salariales nominales entre los peones y albañiles eran similares a los de Buenos Aires y más elevados que los de ciudades cercanas como Santa Fe. Además de la escasez de mano de obra, es posible que los salarios nominales se vieran afectados por la competencia entre las actividades urbanas y las rurales, en un territorio donde la diferenciación espacial de la actividad económica era todavía tenue. A lo largo del período 1760-1810 los salarios nominales de casi todas las categorías estudiadas en este trabajo experimentaron ligeras mejoras, en la mayoría de los casos después de 1780 y hasta 1800. Al respecto, es útil tener en cuenta que entre 1795-1810 en el espacio montevideano se registró un incremento del precio de los alimentos del orden del $70 \%$, de modo que los movimientos alcistas del salario nominal en ocasiones resultaron insuficientes para compensar esa subida.

Las diferencias salariales entre los trabajadores cualificados y los no cualificados eran muy marcadas, reflejando la existencia de premios por cualificación muy superiores a los que han sido dados a conocer para las diversas regiones europeas en la misma época.

Fueron estimadas ratios de bienestar para diez categorías ocupacionales con el mismo método que ha sido utilizado en la literatura comparativa reciente sobre los niveles de vida en América Hispana en el largo plazo. Luego de adaptarla a la oferta local de alimentos y tomando en cuenta algunas consideraciones sobre la alimentación de los montevideanos en la época, fue posible estimar el costo de una cesta de consumo esencial para una familia trabajadora compuesta por dos adultos y dos niños. Desde el punto de vista del poder de compra de su salario, hacia 1800 los trabajadores montevideanos estudiados en este trabajo pueden ser agrupados en dos conjuntos. El grupo de los trabajadores manuales cualificados alcanza ratios de bienestar similares a los de sus pares de las economías europeas más avanzadas de su época (Londres), mientras que por el contrario, el grupo de los trabajadores manuales no cualificados, son comparables a los de sus pares de las ciudades de la Europa menos dinámica en los mismos años (por ejemplo, Milán). Esta dualidad de situaciones requiere comentarios adicionales.

Por un lado, es necesario profundizar en futuras investigaciones sobre las características diferentes de los mercados de trabajo cualificado y no cualificado. A primera vista, parecería que los trabajadores cualificados constituyen un segmento de la oferta de trabajo con ventajas importantes en el mercado laboral de Montevideo, que posiblemente no fueran extensivas a los trabajadores no cualificados.

Por otro lado, es improbable que el grueso de la población ocupada en las faenas poco cualificadas del campo y la ciudad estuviera en una franca situación de pobreza durante todo el período. Se trata de un panorama difícil de compatibilizar con numerosos indicadores económicos y demográficos de 
la región en la misma época, que dan cuenta de un importante crecimiento demográfico, un proceso de expansión de la frontera agrícola y una continuada intensificación de los intercambios. Si bien es concebible un escenario de expansión económica con deterioro del nivel de vida de sectores populares, no es posible explicar la llegada sostenida de inmigrantes a una región donde los salarios reales de los sectores subalternos, comparados con otras regiones americanas, fueran deficientes. Todo indica que la tasa de bienestar obtenida con la metodología propuesta por Allen (2001) y generalizada en los estudios ya mencionados, no puede ser tomada como un indicador fidedigno del bienestar de un amplio conjunto de trabajadores libres ocupados en ramas urbanas y rurales de primera importancia en la economía montevideana. Así, más que una temprana brecha de bienestar entre trabajadores de Europa Nord-occidental y de América Latina que anticipa futuras divergencias macroeconómicas, la brecha entre la ratio de bienestar del albañil montevideano y la del albañil londinense refleja diferentes grados de mercantilización de los factores productivos en Londres y en Montevideo. Concretamente, al menos en el espacio montevideano (no muy diferente de otros más vastos y poblados del Río de la Plata en la misma época), existen numerosos indicios de que el salario no era el componente decisivo en la estructura de los ingresos familiares entre estos sectores subalternos.

Esta hipótesis encuentra asidero lógico en una economía caracterizada por la existencia de recursos abundantes y una trama institucional de Antiguo Régimen que todavía no ha clausurado el acceso a esos recursos por fuera del mercado, para un conjunto de sectores criollos y mestizos. Así, puede decirse que la ratio de bienestar obtenida mediante la metodología que se sigue en este trabajo parece ser un instrumento apropiado para comparar, entre regiones y períodos, niveles de bienestar de ocupaciones por arriba de cierto nivel de cualificación y estabilidad. Pero no es apta para comparar niveles de bienestar entre ocupaciones de baja o ninguna cualificación, donde figuraban como asalariados, de modo intermitente, sectores de la sociedad colonial cuya supervivencia no dependía exclusivamente y quizás, tampoco principalmente, de un salario. Aun cuando por el momento no es posible indicar con precisión el peso de estos sectores en el total de la población activa, parece razonable pensar que en una economía precapitalista como la de este caso, donde las relaciones salariales no eran las relaciones de trabajo más generalizadas ni los mercados de factores tenían las características de mercados modernos auto-regulados en el sentido de (Polanyi 2007 [1944]), existieran amplios sectores de la población económicamente activa que no dependían completamente de un salario para vivir.

En una agenda futura de investigación debe anotarse el desafío de buscar formas alternativas para conocer los niveles de bienestar de estos sectores en economías pre-industriales de recursos abundantes, población escasa y una malla institucional que todavía no cerraba el acceso a los recursos a los recién llegados, al menos para los periodos anteriores a 1810. 
En cuanto a los períodos posteriores, no parece improbable que la ruptura institucional de 1810, así como las guerras de independencia -que en el Río de la Plata se prolongaron hasta 1828- hayan de algún modo clausurado para siempre también las viejas oportunidades de acceso a los ganados y las tierras, y sentado las bases para el desarrollo de nuevas relaciones de trabajo, donde el salario irá ganado creciente centralidad como ingreso de los hogares de los sectores populares a medida que avanzó el siglo XIX.

\section{FUENTES Y PUBLICACIONES OFICIALES}

Archivo General de Indias: Buenos Aires, 445-446 y 448.

Archivo General de la Nación (Uruguay), Archivo General Administrativo: Libro 161 y Cajas cronológicas 1758-1800: $\mathrm{N}^{\mathrm{os}} 25,30,37,48,51,55,72,85$, $88,94,99,106,109,116,118,122,125,128,140,145,154,157,190,221,234$, 235, 243, 258, 274, 282, 319, 322, 328, 334.

Archivo General de la Nación (Argentina), Sala IX, 03-02-05, División Colonia, Sección Gobierno Montevideo, Iglesia Matriz, Cuentas, 1781-1808.

\section{REFERENCIAS}

Acemoglu, D.; Johnson, S., y Robinson, J.A. (2001): «The Colonial Origins of Comparative Development: An Empirical Investigation». The American Economic Review 91 (5), pp. 1369-1401.

Acemoglu, D.; Johnson, S., y Robinson, J.A. (2002): «Reversal of Fortune: Geography and Institutions in the Making of the Modern World Income Distribution». The Quarterly Journal of Economics 117 (4), pp. 1231-1294.

Acemoglu, D., y Robinson, J. (2012): Why Nations Fail? The Origins of Power, Prosperity and Poverty. Estados Unidos de América: Random House.

Allen, R.C. (2001): "The Great Divergence in European Wages and Prices from the Middle Ages to the First World War». Explorations in Economic History 38 (4), pp. 411-447.

Allen, R.C.; Bassino, J.P.; Ma, D.; Moll-Murata, C., y Van Zanden, J.L. (2011): «Wages, Prices, and Living Standards in China, 1738-1925: In Comparison with Europe, Japan, and India». The Economic History Review 64 (1), pp. 8-38.

Allen, R.C.; Murphy, T.E., y Schneider, E.B. (2012): "The Colonial Origins of the Divergence in the Americas: A Labor Market Approach». The Journal of Economic History 72 (4), pp. 863-894.

Allen, R.C.; Murphy, T.E., y Schneider, E.B. (2015): «Una de cal y otra de arena. Building Comparable Real Wages in a Global Perspective». Revista de Historia Económica/Journal of Iberian and Latin American Economic History 33 (1), pp. 61-75.

Amaral, S. (1987): "Trabajo y trabajadores rurales en Buenos Aires a fines del siglo XVIII». Anuario del IEHS 2, pp. 33-42.

Arroyo-Abad, L.; Davies, E., y Van Zanden, J.L. (2012): «Between Conquest and Independence: Real Wages and Demographic Change in Spanish America, 15301820». Explorations in Economic History 49 (2), pp. 149-166. 
Arroyo-Abad, L., y Van Zanden, J.L. (2015): «Optimistic but Flawed? A Reply». Revista de Historia Económica/Journal of Iberian and Latin American Economic History 33 (1), pp. 77-82.

Arroyo Abad, L. (2013): «Inestabilidad, costo de vida y salarios reales en Venezuela en el siglo XIX». América Latina en la historia económica 20 (3), pp. 114-137.

AssunçAO, F. (1978): "Presencia de las Misiones Jesuíticas en el territorio uruguayo", en La Iglesia en el Uruguay. Montevideo: Cuadernos del ITU.

Bentancur, A.A. (1997): El puerto colonial de Montevideo. Montevideo: Universidad de la República, Departamento de Publicaciones de la Facultad de Humanidades y Ciencias.

BroadberRy, S., y GuPTA, B. (2006): «The Early Modern Great Divergence: Wages, Prices and Economic Development in Europe and Asia, 1500-1800». The Economic History Review 59 (1), pp. 2-31.

Bruhn, M., y Gallego, F.A. (2012): «Good, Bad, and Ugly Colonial Activities: Do They Matter for Economic Development?». Review of Economics and Statistics 94 (2), pp. 433-461.

Capillas De Castellanos, A. (1968): Montevideo en el siglo XVIII. Montevideo: Nuestra Tierra.

Challú, A., y Gómez-Galvarriato, A. (2015): «Mexico's Real Wages in the Age of the Great Divergence, 1730-1930». Revista de Historia Económica/Journal of Iberian and Latin American Economic History 33 (1), pp. 83-122.

De Azara, F. (1943 [1801]): Memoria sobre el estado rural del Río de la Plata y otros informes. Buenos Aires: Bajel.

Djenderedjan, J., y Martirén, J.L. (2015): Are Salaries a so Useful Tool to Build Up Comparable Standards of Living? Some Caveats Concerning Salary Elements, Available Currencies, Debts and Credit in Pre-Modern Rio de la Plata Region, 17701830. Ponencia en 17th World Economic History Congress. Kyoto.

DJENDEREDJIAN, J., Y MARTIRÉN, J.L. (2015): «Precios, producto agrario y niveles de vida en las fronteras rioplatenses, 1700-1810: una nueva mirada sobre el crecimiento económico tardocolonial». Revista de Historia Económica/Journal of Iberian and Latin American Economic History 33 (1), pp. 123-152.

DJENDEREDJIAN, J., Y MARTIRÉN, J.L. (2016): «Los aforos de Alcabalas como fuente útil para el estudio de los precios en el Río de la Plata: metodología e interpretación sobre su evolución en la etapa virreinal (1782-1810)». Folia Histórica del Nordeste 26, pp. 74-94.

Dobado-González, R. (2015): «Pre-Independence Spanish Americans: Poor, Short and Unequal... or the Opposite?». Revista de Historia Económica/Journal of Iberian and Latin American Economic History 33 (1), pp. 15-59.

Dobado, R., y García Montero, H. (2010): «Colonial Origins of Inequality in Hispanic America? Some Reflections Based on New Empirical Evidence». Revista de Historia Económica/Journal of Iberian and Latin American Economic History 28 (2), pp. 253-278.

Fradkin, R., y GaRavaglia, J.C. (2004): En busca de un tiempo perdido: la economía de Buenos Aires en el país de la abundancia, 1750-1865. Buenos Aires: Prometeo.

FurLONG, G.S.J. (1933): Los Jesuitas y la cultura rioplatense. Montevideo: Imprenta Urta y Curbelo.

Gelman, J., y Moraes, M.I. (2014): «Las reformas borbónicas y las economías rioplatenses: cambio y continuidad», en J. Gelman, E. Llopis, y C. Marichal (eds.), Iberoamérica y España antes de las independencias, 1700-1820. Crecimiento, reforma y crisis. México: El Colegio de México - Instituto Mora, pp. 31-74. 
Gelman, J., y Santilli, D. (2015): A Consumption Basket of Buenos Aires, XIXth Century. The Bare - Bone Basket and the Welfare Ratio. Ponencia en 17th World Economic History Congress. Kyoto.

Gelman, J., y Santilli, D. (2015): «Salarios y precios de los factores en Buenos Aires, 1770-1880: Una aproximación a la distribución funcional del ingreso en el largo plazo". Revista de Historia Económical Journal of Iberian and Latin American Economic HIstory 33 (1), pp. 153-186.

GonzÁlez Mariscal, M. (2014): "En torno al debate sobre los niveles de vida en el Antiguo Régimen: prospección crítica, mejoras metodológicas y comparación de resultados. El caso de Sevilla, 1521-1800". Ponencia en IV Congreso Latinoamericano de Historia Económica. Bogotá: Utadeo.

Johnson, L. (1990): «Salarios, precios y costo de vida en el Buenos Aires colonial tardío. Boletín del Instituto de Historia Argentina y Americana». Dr. Emilio Ravignani 2, pp. 133-157.

Johnson, L., y TANDETER, E. (1992): Economías coloniales. Precios y salarios en América latina, siglo XVIII. México: Fondo de Cultura Económica.

Johnson, L. (1992): «La historia de precios de Buenos Aires durante el período virreinal», en L. Johnson, y E. Tandeter (eds.), Economias coloniales: precios y salarios en America Latina siglo XVIII, Mexico: Fondo de Cultura Económica. 153-190.

Luque Azcona, E. (2003): "Mano de obra y construcción del complejo defensivo de Montevideo: condiciones laborales y respuestas al orden establecido, 1740-1800", ponencia en Terceras Jornadas de Historia Económica. Montevideo.

Llopis, E., Y Montero, H.G. (2011): «Precios y salarios en Madrid, 1680-1800». Investigaciones de Historia Económica- Economic History Reserarch 7 (2), pp. 295-309.

Llorca-Jaña, M., y Navarrete-Montalvo, J. (2015): "The Real Wages and Living Conditions of Construction Workers in Santiago de Chile During the Later Colonial Period, 1788-1808». Investigaciones de Historia Económica-Economic History Research 11 (2), pp. 80-90.

MAEDER, E.J. (1992): Misiones del Paraguay: conflictos y disolución de la sociedad guaraní (1768-1850). Madrid: Fundación MAPFRE.

MAYo, C. (1987): «Sobre peones, vagos y malentretenidos: el dilema de la economía rural rioplatense durante la época colonial». Anuario del IEHS 2, pp. 25-32.

Moraes, M.I., y Stalla, N. (2011): Antes y después de 1810: escenarios en la historia de las exportaciones rioplatenses de cueros desde 1760 hasta 1860. DT SEHA $\mathrm{N}^{\circ} 11-10$, Sociedad Española de Historia Agraria.

Moraes, M.I. (2012): "El paisaje agrario montevideano en la segunda mitad del siglo XVIII: una caracterización de sus sistemas agrícolas y ganaderos". Ponencia en el $I I$ Congreso Latinoamericano de Historia Económica, 23-27 de octubre, Bariloche.

Moraes, M.I. (2014): «Tendencias y coyunturas agrarias del Litoral rioplatense, 1760-1800: un análisis cuantitativo». Investigaciones de Historia Económica 10 (1), pp. 22-33.

Moraes, M.I., y Thul, F. (2015): Evolución del precio de una canasta de consumo en Montevideo entre 1760-1810. Proyecto ANII-Fondo Clemente Estable $\mathrm{N}^{\circ}$ 6595, Informe $\mathrm{N}^{\circ} 2$ (inédito), Montevideo.

North, D.C.; Summerhill, W., y Weingast, B.R. (1999): «Order, Disorder and Economic Change: Latin America vs. North America». California: UCLAWorking Paper.

PolanyI, K. (2007 [1944]): La gran transformación: crítica del liberalismo económico. México: Fondo de Cultura Económica.

Pollero, R. (2015): "¿Qué nos es posible conocer respecto al inicio del cambio demográfico? Una aproximación a las fases tempranas de la transición epidemiológica en Montevideo». Revista Latinoamericana de Población 16, pp. 9-34. 
Pollero, R. (2016): Historia demográfica de Montevideo y su campaña, 1756-1860. Montevideo: Facultad de Ciencias Sociales, Universidad de la República.

Pollero, R., y SAGASETA, G. (2015): Serie estimada de la población total para la jurisdicción de Montevideo entre 1760-1860. Proyecto ANII-Fondo Clemente Estable $\mathrm{N}^{\circ}$ 6595, Informe $\mathrm{N}^{\circ} 1$ (inédito), Montevideo.

SANDRÍn, M. (2013): «La actividad económica de los asentistas de víveres de la Marina de Montevideo, 1770-1810 21». América Latina en la historia económica 21 (1), pp. 92-114.

Thul, F. (2013): «Trabajo libre y esclavo de la población afrodescendiente en Montevideo, 1835-1841. Los registros de papeletas de conchabo para el estudio del mercado de trabajo». Revista Uruguaya de Historia Económica 3 (4), pp. 31-45.

Thul, F. (2015): Relaciones laborales en el sector de la construcción en el Montevideo tardo-colonial. La construcción de las fortificaciones y de la Iglesia Matriz, 17601808. Ponencia en 6as. Jornadas de Historia Económica. Montevideo: Asociación Uruguaya de Historia Económica.

VAn Zanden, J.L. (2009): "The Skill Premium and the 'Great Divergence'». European Review of Economic History 13 (1), pp. 21-153.

Vicario, C. (2015): The Formation of Human Capital in Pre-Modern Latin America. Tubingen: Eberhard Karls Universität Tübingen. 